\title{
A Descriptive Study: Observing Behavioral Patterns of Preschool Children in Turkey and Belgium
}

\author{
Sakire Ocak Karabay', Derya Sahin'1, Anita Swennen² \\ ${ }^{1}$ Preschool Education Program, Faculty of Education, Ege University, Izmir, Turkey \\ ${ }^{2}$ College Department of Teacher Training, Katholieke Hogeschool Limburg University, Hasselt, Belgium \\ Email: sakire.ocak@ege.edu.tr, derya.sahin@ege.edu.tr
}

Received 16 January 2015; accepted 4 February 2015; published 10 February 2015

Copyright (C 2015 by authors and Scientific Research Publishing Inc.

This work is licensed under the Creative Commons Attribution International License (CC BY). http://creativecommons.org/licenses/by/4.0/

(c) (i) Open Access

\begin{abstract}
Children should have flexible and adaptable repertoire to accomplish qualified social skills. In order to achieve this, teachers have a significant responsibility to propose crucial opportunities to children during classroom activities. Although teachers prefer to use universal approaches to promote prosocial behaviors rather than to remove maladaptive behaviors, cultural issues in social problem solving skills would be effective on their behavioral pattern of treatment to children. In this study, it was evaluated to see possible differences between Turkish and Flemish preschool children in their behavioral patterns. It was found that there was only significant difference in prosocial dimension of Drexel Early Childhood Behavior Rating Scale (Shure, 2005). In aggression and introversion dimensions, it was not found any significant difference between the two groups. However the mean scores of Flemish preschoolers in aggression dimension of the scale were found less than Turkish preschoolers. Findings were discussed based on literature.
\end{abstract}

\section{Keywords}

Preschool Education, Prosocial Behaviors, Classroom Organization, Cultural Differences

\section{Introduction}

Social problem solving skills of children and their capacity to solve problems are very crucial when they try to cope with various problem situations in classroom. Although some of children have enough capacity to achieve this, some children cannot maintain well-adjusted relationships because they are not competent to show prosocial behavior for positive interactions (Hennessy \& Martin, 1992). It has been suggested that children should 
have flexible and adaptable repertoire to accomplish qualified social skills such as identifying their own and other's feelings, encouraging skills associated with listening and paying attention, taking responsibility of their decisions, ability to cope with frustration, successful emotional control, managing their own's feelings and behaviors, building positive relationships (Spence, 2003; Zins, Bloodworth, Weissberg, \& Walberg, 2007; Powell, Dunlap, \& Fox, 2006; Shure \& Spivack, 1980, 1982, 1988; Webster-Stratton, Reid, \& Hammond, 2001; Reid, Webster-Stratton, \& Hammond, 2007).

In this respect, teachers have a key role to let children to deal with problems more competently and create more peaceful classroom atmosphere. According to Bingham (1983), teachers first should be aware of social problems emerging between children as a natural process of interactions. Teachers have a significant responsibility to make possible to enrich interpersonal relationships of children because of several opportunities to achieve this goal. Teachers can integrate specific problem solving training into their curriculum, provide students to practice those skills and promote cognitively based newly learned behavioral skills in the classroom (Zins et al., 2007; Webster-Stratton \& Reid, 2008). Teaching children to think of more prosocial solutions to their problems and to evaluate which solutions are better choices and more likely to lead to positive consequences than others which would be supportive to improve their alternative problem solving thinking skills.

Another crucial issue is to arrange classroom with various educational materials stimulating children to initiate involvement in those activities which should be scheduled and planned systematically. The complexity of those activities also determines the likelihood of children's positive involvement in such activities. Children who are fully involved in classroom activities are unlikely to engage in disruptive behavior (Powell, Dunlap, \& Fox, 2006); they tend to solve problems by using more peaceful ways cooperatively (Goffin \& Tull, 1985; Honig \& Wittmer, 1996). When curricula has been evaluated, it could be easily noticed that teachers usually use typical songs, stories, role-plays, and other activities in order to promote social emotional learning abilities of children in early childhood education (Denham \& Burton, 2003). Those activities and approaches or methods have been used to keep well-being of children as a universal point of view. It has been tried to promote the positive prosocial dimension rather than preventive efforts by considering individual differences (Mayer, 1995; Shure, 2001).

Although teachers prefer to have universal approaches or to use general methods to succeed promoting prosocial behaviors rather than removing maladaptive behaviors, cultural, background, social welfare, economic conditions, educational viewpoint of that nationality, school policies would be effective on their behavioral pattern of treatment to children. Those all, in turn, may affect different behavioral dimensions of children in a wide range from negative to positive in classroom settings. For this reason it is needed to address differences in behavioral dimensions of children in diverse cultures to catch constructive curriculum to enhance social problem solving skills of children.

The goal of this study is to evaluate whether there would be differences between Turkish and Flemish preschool children in their behavioral patterns. It was hypothesized that while prosocial behaviors of Flemish preschoolers were better than Turkish preschoolers, aggressive behaviors were less than Turkish peers. It was not expected any difference between two groups in terms of introversion dimension.

\section{Method}

Five (57\% girls, 43\% boys) and 6 (49\% girls, 51\% boys) years old 53 Turkish and Flemish children who have been attending public preschools both full-time and part-time in Izmir (Turkey) and in Hasselt (Belgium) were participated in the study. Twenty six children were from Flemish preschools, 27 children were from Turkish preschools. There were no significant differences between two groups in terms of gender and age. Children who had no physical, cognitive, visual and hearing disabilities were randomly selected from the classroom list considering gender ratio.

\subsection{Instruments}

Drexel Early Childhood Behavior Rating Scale (Shure, 2005). This is a teacher, parent and professional rated scale including 12 items which is used to specify behavioral dimensions of children in their interactions. Those behavioral dimensions cover overt and relational aggressive behaviors, prosocial behaviors and also introversive behavior patterns. Evidence of face validity of the scale includes pre intervention to post intervention findings in expected directions.

The validity and reliability studies of the scale have been completed in Turkish sample. Factor analysis was 
conducted with principal components and Kaiser Normalization according to varimax rotation. Items were loaded into three factors and this factor model was found to explain $80.6 \%$ of total variance. These factors have been identified based on their content. The first factor was named as "Aggression" which was explaining 30.6\% of total variance; the second one is "Prosocial" explaining $27.9 \%$ of total variance; the third one is "Introversion" explaining $22.1 \%$ of total variance. According to findings, construct validity was found concordant with the original validation studies.

Internal reliability of the scale has been confirmed also. Internal reliability Cronbach alphas were found as 0.93 for aggressive subscale, 0.86 for prosocial subscale, 0.63 for Introversion subscale. The percentage of inter coder reliability was found around $90 \%$.

\subsection{Procedure}

The present study was designed to collect descriptive data by using non-participant observation method. Observations in Turkey were conducted by Turkish researchers who were psychologists experienced in preschool education one of whom has Ph.D. degree in clinical psychology and the other one has also Ph.D. degree in developmental psychology. On the other hand in Belgium, children were observed by one of the Turkish researchers and also experienced Flemish educator in preschool teaching. Before starting observation process, researchers agreed on what should be defined under the title of aggression, prosocial, withdrawn behaviors considering DECB rating scale. Turkish preschool children were observed then Flemish observations were completed. Before the observation sessions started, the head and the teachers of participant preschoolers was briefly informed about the process and the duration of the study by the researchers. Observations were accomplished in free play time of Turkish preschoolers only for an hour in their daily activities because of more didactic and structured curriculum in Turkish preschools compared to Flemish preschools. In Turkish preschool education the curriculum has been shaped by recent educational approaches emphasizing active participation of children in learning process via multiple intelligences and project approach. On the other hand in Flemish preschools more extended flexible, innovative, child initiated curriculum was implemented based on Experiential Education Approach. In this approach preschool children were led to select activities supporting innovative learning based on their interests. Therefore it could be possible to observe Flemish preschool children because of plenty of time in their free choice activities. Children in both groups were observed in their free play time in order to recognize their behavior patterns and interactions in their natural settings. For this reason teachers were asked to let children to be free in classroom setting as much as possible. At the beginning of observation the researchers were introduced to children to whom it was told that their plays would be observed during that time. Observations took 15 minutes for each child, 10 minutes for observing, 5 minutes for coding by using Drexel Early Childhood Behavior Rating Scale (DECB). Every child was observed twice at different times to follow possible alternative changes in their interaction styles.

\section{Findings}

In the direction of main goal of the present study, the independent samples $t$ test was conducted to examine if there was any differences between the two groups in terms of DECB Rating Scale which covers three behavioral dimensions; aggression, prosocial, and introversion. As it is shown in Table 1, there was only significant difference in prosocial dimension of DECB Rating Scale (t(51) $=-3.905, p<0.01)$. In aggression and introversion

Table 1. The independent samples t-test comparing Turkish and Flemish preschooler's DECB rating scale--behavior subscales.

\begin{tabular}{ccccccccc}
\hline DECB Rating Scale-Behavior Subscales & Country & $\mathrm{N}$ & $\bar{X}$ & $\mathrm{SD}$ & $\mathrm{df}$ & $\mathrm{T}$ & $p$ \\
\hline \multirow{2}{*}{ DECB Aggression } & Turkey & 27 & 11.70 & 5.81 & & & 1.410 & 0.165 \\
& Belgium & 26 & 9.65 & 4.74 & 51 & & \\
DECB Prosocial & Turkey & 27 & 14.77 & 1.87 & 51 & -3.905 & $0.000^{*}$ \\
& Belgium & 26 & 17.15 & 2.53 & & & \\
DECB İntroversion & Turkey & 27 & 11.29 & 5.18 & 51 & -0.322 & 0.749 \\
& Belgium & 26 & 11.69 & 3.67 & & & \\
\hline
\end{tabular}


dimensions, it was not found any significant difference between the two groups $(\mathrm{t}(51)=1.410, p>0.05, \mathrm{t}(51)=$ $-0.322, p>0.05)$. However the mean scores of Flemish preschoolers in aggression dimension of the scale were found less than Turkish preschoolers. This finding will be discussed later based on educational framework in both of the countries.

\section{Discussion}

In the present study, it was evaluated that if there would be differences between Turkish and Flemish preschool children in terms of behavioral subscales of DECB rating scale. As it was hypothesized Flemish preschool children were found better than Turkish peers in terms of prosocial behaviors although the mean scores of Flemish preschoolers were higher than Turkish preschoolers. Additionally, both of the groups were not differed significantly considering introversion dimension. However it was unexpected to find that there was no significant difference between the two groups related to aggression dimension of the scale.

As it was previously mentioned, promoting prosocial dimension of behaviors has been seen as a universal treatment in keeping well-being of children. Therefore the findings of the present study can be supported by this point of view. In this study the finding that revealed more prosocial behaviors of Flemish preschoolers could be interpreted as parallel to the approach specified above. Promoting prosocial behaviors could be seen the starting point for decreasing frequency of maladaptive behaviors. In order to achieve this goal, there are lots of issues that should be considered. One of those is the classroom settings and also educational framework that has been displayed for children in the class.

Preschool teachers can arrange classroom, routines and schedules that provide important opportunities for creating supportive environments. It has been suggested that whole classroom should be divided into small and well-defined corners to achieve effective and innovative learning areas so that it would be possible to keep children's attention based on their preferences. It is also critical to design clear paths to control chaotic settings and also to use simple system to limit the number of children at one time in any corner. Providing lots of toys and educational materials would prevent conflicts to encourage cooperation by exploring and expressing feelings (Denham \& Burton, 2003). The physical environment which includes well-designed learning centers, traffic paths within the classroom and sufficient number of materials and equipment would foster positive and creative interactions among children. In other words, classroom schedules, routines and activities provide valuable tools for preventing problems by providing comfortable spaces for children to spent enjoyable time (Powell, Dunlap, \& Fox, 2006).

Those were all the reasons why it has been found that there was a significant difference between Turkish and Flemish preschoolers. Since the classroom settings in Turkish preschools have usually been designed by limited opportunities, it is likely to occur conflictual situations. Compared to Flemish preschools, the learning corners have not been divided into effective and small areas based on children's interests in Turkish preschool classrooms. In addition to this, it cannot be assumed that sufficient number and variety of materials could be provided for children. Although it has been conducted a child-centered approach, most of the time teachers seem to give direct guidance whatever has gone at the moment. However, in Belgium, most of the time the child initiated activities have been carried out considering children's interests and competencies. On the contrary, in Turkish preschools, teachers usually have suggestions for activities by using direct instruction instead of supporting children to explore different kinds of learning opportunities.

Planned and scheduled daily routines would be helpful for children to let them to feel comfortable by removing uncertainty. Moreover it is possible to change activities before children get bored. This kind of planned activities and arrangements would decrease the occurrence of misbehaviors of children by reducing waiting times and changing activities when boredom signals emerge (Denham \& Burton, 2003). In other words, developing clear and positive classroom rules and predictable schedules and routines by discussing those with children would make possible to create peaceful classroom settings (Webster-Stratton \& Reid, 2008). This kind of classroom arrangements is more clearly conducted in Flemish preschools compared to Turkish preschools. Children regularly have daily routines; starts with greetings, sharing experiences and emotions then continues with discovering various learning areas by focusing on enriched environment contributing to their positive emotion and behaviors. By this way, they can effectively utilize their cognitive emotional and behavioral resources to learn and to develop themselves (Denham \& Burton, 2003).

Although all young children have capacity to benefit from social and emotional foundations of learning, there is a need for universal programming with individualization which is the essential element of such a view (Den- 
ham \& Burton, 2003). In this process, it could be possible to achieve interactive education both to improve academic skills and also socio-emotional framework of children by organizing flexible classroom environment.

\section{References}

Bingham, A. (1983). Çocuklarda problem çözme yeteneklerinin geliştirilmesi. [Improving Problem Solving Skills of Children]. F. Oğuzkan (Trans.), İstanbul: MEB Basımevi.

Denham, S. A., \& Burton, R. (2003). Social and Emotional Prevention and Intervention Programming for Preschoolers. New York: Kluwer Academic/Plenum Publishers. http://dx.doi.org/10.1007/978-1-4615-0055-1

Goffin, S. G., \& Tull, C. Q. (1985). Problem Solving Encauraging Active Learning. Young Children, 40, 28-32.

Hennessy, E., \& Martin, S. (1992). Children and Day Care. London: Paul Chapman Publishing Ltd.

Honig, A. S., \& Wittmer, D. S. (1996). Helping Children Became More Prosocial: İdeas for Classrooms, Families, Schools, and Communities. Young Children, 51, 62-70.

Mayer, G. R. (1995). Preventing Antisocial Behavior in the Schools. Journal of Applied Behavior Analysis, 28, 467-478. http://dx.doi.org/10.1901/jaba.1995.28-467

Powell, D., Dunlap, G., \& Fox, L. (2006). Prevention and Intervention for the Challenging Behaviors of Toddlers and Preschoolers. Infants and Young Children, 19, 25-35. http://dx.doi.org/10.1097/00001163-200601000-00004

Reid, M. J., Webster-Stratton, C., \& Hammond, M. (2007). Enhancing a Classroom Social Competence and Problem-Solving Curriculum by Offering Parent Training to Families of Moderate- to High-Risk Elementary School Children. Journal of Clinical Child and Adolescent Psychology, 36, 605-620. http://dx.doi.org/10.1080/15374410701662741

Shure, M. B. (2001). What's Right with Prevention? Commentary on "Prevention of Mental Disorders in School-Aged Children: Current State of the Field. Prevention and Treatment, 4. http://journals.apa.org/prevention/volume4/pre0040001a.html

Shure, M. B. (2005). Drexel Early Childhood Behavior (DECB) Rating Scale. Philadelphia, PA: Drexel University.

Shure, M. B., \& Spivack, G. (1980). Interpersonal Problem Solving as a Mediator of Behavioral Adjustment in Preschool and Kindergarden Children. Journal of Applied Developmental Psychology, 1, 29-44. http://dx.doi.org/10.1016/0193-3973(80)90060-X

Shure, M. B., \& Spivack, G. (1982). Interpersonal Problem-Solving in Young Children: A Cognitive Approach to Prevention. American Journal of Community Psychology, 10, 341-356. http://dx.doi.org/10.1007/BF00896500

Shure, M. B., \& Spivack, G. (1988). Interpersonal Cognitive Problem Solving. In R. H. Price, E. L. Cowen, R. P. Lorion, \& J. M. McKay (Eds.), 14 Ounces of Prevention: A Casebook for Practitioners. Washington DC: American Psychological Association.

Spence, S. H. (2003). Social Skills Training with Children and Young People: Theory, Evidence and Practice. Child and Adolescent Mental Health, 8, 84-96. http://dx.doi.org/10.1111/1475-3588.00051

Webster-Stratton, C., \& Reid, J. (2008). The Incredible Years Classroom Management Teacher Training Program: Content, Methods, and Process. http://www.son.washington.edu/centers/parenting-clinic/opendocs/teachertrainingprogram.pdf

Webster-Stratton, C., Reid, J., \& Hammond, M. (2001). Social Skills and Problem-Solving Training for Children with Early-Onset Conduct Problems: Who Benefits? Journal of Child Psychology and Psychiatry, 42, 943-952.

http://dx.doi.org/10.1111/1469-7610.00790

Zins, J. E., Bloodwoth, M. R., Weissberg, R. P., \& Walberg, H. J. (2007). The Scientific Base Linking Social and Emotional Learning to School Success. Journal of Educational and Psychological Consultation, 17, 191-210. http://dx.doi.org/10.1080/10474410701413145 
Scientific Research Publishing (SCIRP) is one of the largest Open Access journal publishers. It is currently publishing more than 200 open access, online, peer-reviewed journals covering a wide range of academic disciplines. SCIRP serves the worldwide academic communities and contributes to the progress and application of science with its publication.

Other selected journals from SCIRP are listed as below. Submit your manuscript to us via either submit@scirp.org or Online Submission Portal.
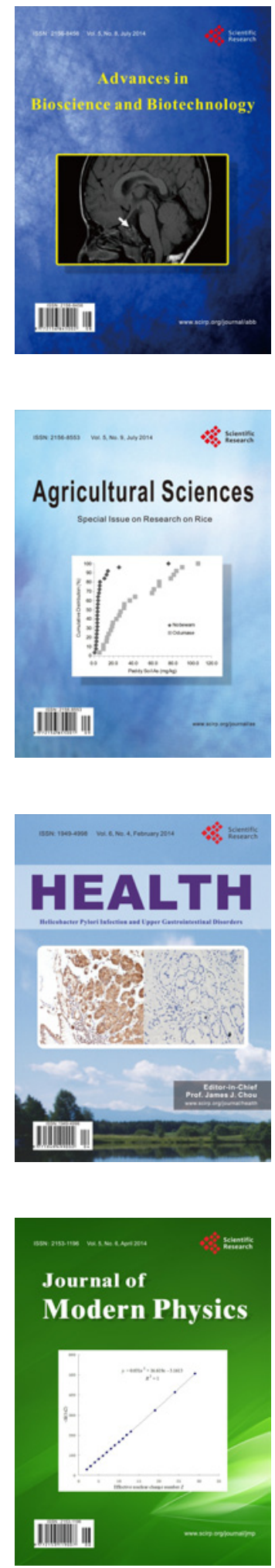
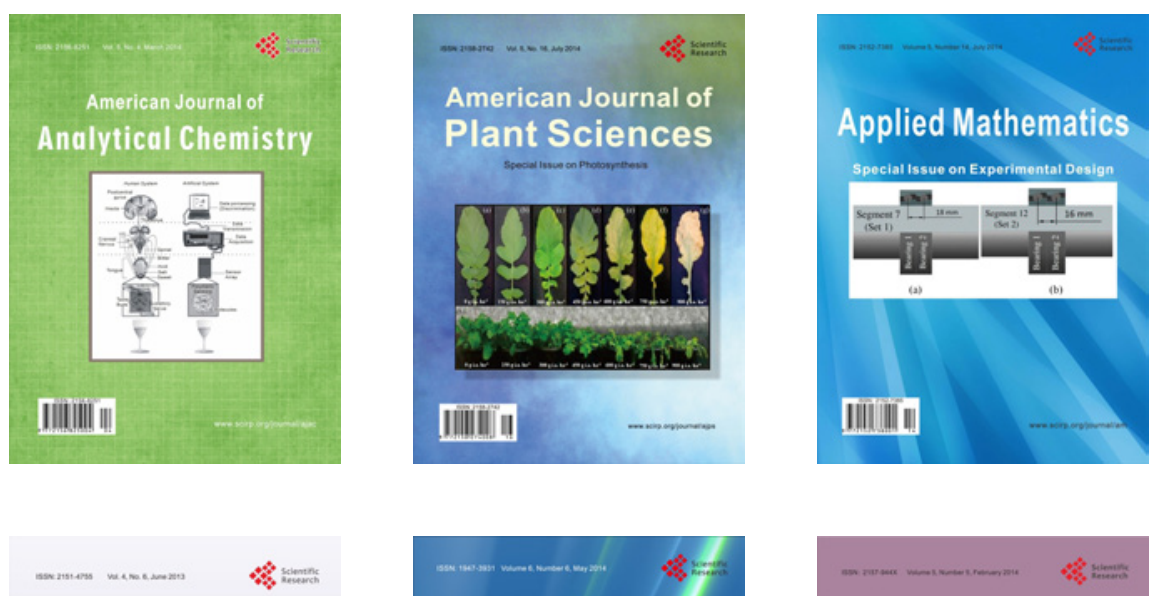

Creative Education
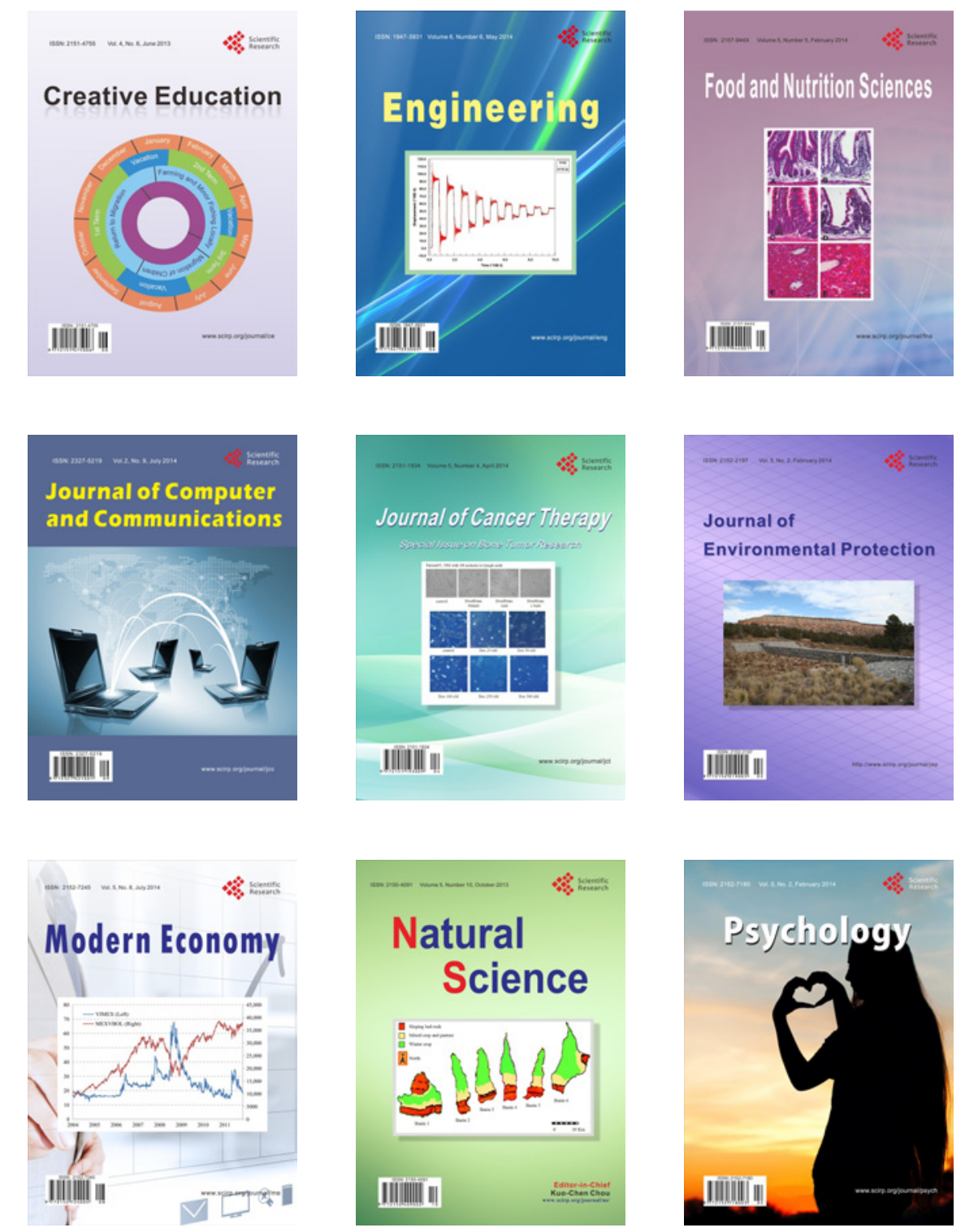